\title{
Impact of Brucellosis on Interleukin -23 Level, Acid Phosphates and Some Other Trace Elements
}

\author{
Khalil Ismail A. Mohamed ${ }^{1 *}$, Wifaq M. Ali Al-Wattar ${ }^{1}$, Ghada Ibrahim Taha², Saad \\ Hasan Mohammed Ali ${ }^{1}$, Huda Q. Mohammed Abu-Al-Ess ${ }^{1}$, Suha A. Al-Fukhar ${ }^{1}$ and \\ Jinan M. Mousa ${ }^{1}$
}

${ }^{1}$ Clinical Communicable Diseases Research, College of Medicine, University of Baghdad, Baghdad, Iraq. ${ }^{2}$ Department of Basic Sciences, College of Dentistry, University of Baghdad, Baghdad, Iraq.

\begin{abstract}
The study was carried out during a period of February 2017-July 2018 for the detection of brucellosis in 128 suspected patients with age group range from 17 - 69 years, who attended to Baghdad teaching hospitals, that had been examined and defined as suspected cases by specialized physician with the recording of clinical manifestation. The diagnosis done by Rose Bengal test (RBT) method, a blood sample was taken from each patients as well as other $\mathbf{3 0}$ healthy control matching in age and gender. The study included measurement of the concentration of Interleukin-23, activity of Acidphosphatase, Copper and Zinc in sera of patients and healthy control. The result indicated that Rose Bengal test positive in 18 cases, 12 with a titer of $1: 160$ and 6 cases with a titer of 1:320. The Level of IL-23, Acid phosphatase increased significantly, with no statistical difference in copper and zinc concentration in both interval ages of patients sera in comparison with healthy control.
\end{abstract}

Keywords: Brucellosis, Interleukin-23, Acidphosphatase, Copper , Zinc.

\footnotetext{
*Correspondence: dr.alkarkhi@gmail.com

(Received: 09 September 2018; accepted: 20 October 2018)

Citation: Khalil Ismail A. Mohamed, Wifaq M. Ali AI-Wattar, Ghada Ibrahim Taha, Saad Hasan Mohammed Ali, Huda Q. Mohammed Abu-Al-Ess, Suha A. Al-Fukhar, and Jinan M. Mousa, Impact of Brucellosis on Interleukin -23 Level, Acid Phosphates and Some Other Trace Elements, J Pure Appl Microbiol., 2018; 12(4):2011-2016. http://dx.doi.org/10.22207/JPAM.12.4.37
}

(c) The Author(s) 2018. Open Access. This article is distributed under the terms of the Creative Commons Attribution 4.0 International License which permits unrestricted use, sharing, distribution, and reproduction in any medium, provided you give appropriate credit to the original author(s) and the source, provide a link to the Creative Commons license, and indicate if changes were made. 


\section{INTRODUCTION}

Brucellosis is one of a bacterial Zoonotic illness that affecting animals and man worldwide ${ }^{1,2,3}$. Brucella species are cocco-bacilli gram-negative bacteria, they have many routes of transmission including: direct contact with animals or environment, consuming of uncooked animal product $^{4}$. The transmission from person to person is rare ${ }^{5,6}$, but they have been reported the disease transmission in association with Transfusion of blood and transplantation of bone marrow ${ }^{5}$. The Brucella infection in human either acute or chronic disease continue for many years ${ }^{5,7}$. There are four Brucella species that recognized as a human pathogens; Brucella melitensis, Brucella abortus, Brucella canis and Brucella suis, with their animal reservoirs of sheep and goats, cattle, dogs and swine respectively ${ }^{6,7}$.

Brucellosis is a pyrogenic disease without specified symptoms, but it can cause localized effects in the organ systems ${ }^{8}$. Human Malta fever have an incubation period from five days to five months ( $2-3$ weeks typically) $)^{2,9}$. Clinical symptoms vary widely from patient to patient and ranging from asymptomatic disease to severe illness but they may include recurrent fever, sweats mainly in the night, sleeplessness, arthralgia, headaches, fatigue, malaise, neuralgic symptoms and ache in joints, muscles, and-or back ${ }^{9,10}$. Some symptoms and signs can continue for a long time but others may not re-occur, including arthritis, recurrent fever, endocarditis, swelling of liver and-or spleen, swelling of testicles, neurologic symptoms ( $5 \%$ of all cases), and chronic fatigue (10) Brucella spp. are facultative intracellular pathogens which resist killing by neutrophils, replicate inside macrophages and in "non-professional" phagocytes and maintain a long lasting interaction with the host cells.

Therefore, host control of infection requires a set of cells and factors like $C D^{4+}$ and $C D^{8+}$ T lymphocytes, T-helper 1(Th1) type cytokines such as (IFN $\gamma$ ) and TNF $\alpha$, and activated macrophages and dendritic cells (DC) which together promote a complex response against Brucella. It has been postulated that Th1 cytokines contribute to control Brucella infection ${ }^{11}$. Interleukin-12, chiefly a product of antigen-presenting cells (APC), is usually critical for the development of Th1 responses ${ }^{12,13}$.
IL-10 is an anti-inflammatory cytokine secreted by $T$ cells and macrophages. It interacts with the IL-10 receptor and like IFN- $\gamma$, signals through the Jack/Stat signaling pathway ${ }^{14}$. It is known to down regulate Th1 response during Brucellosis ${ }^{15,16}$. In this study the level of interleukin-23, Acidphosphatase and Copper with Zinc determined in patients with brucellosis in comparison with healthy control matched in age and gender especially Immunity and resistance to infection is affected by the nutritional status as Micronutrients such as $\mathrm{Zn}$ and Cu may affect and modulate immune responses.

\section{MATERIALS AND METHODS \\ Studied groups}

The study carried out during the period from (February2017- July2018), studied group were involved Suspected patients their age range between 17-69 years. Blood samples were obtained from a total of 128 patients clinically suspected with Brucellosis that had been examined and defined as suspected cases by specialized physician with the recording of clinical manifestation.

\section{Blood samples}

Five $\mathrm{mL}$ of venus blood was obtained from each patients and collected in sterilized screw cap plastic tube, blood samples were left for $30 \mathrm{~min}$. at room temperature, then centrifuge at $3000 \mathrm{rpm}$ for five minute, then the serum for each sample was collected in eppendorf tubes and then test for Brucellosis and stored in deep freeze at $-20^{\circ} \mathrm{C}$ until the time for using. The current study included Immunological \& Clinical biochemical aspects in comparison with healthy control.

\section{Rose Bengal test (RBT)}

RBT was carried out according to ${ }^{17}$ with Brucella abortus 599 antigen (Spinreact SA, Gerona, Spain). Briefly, 30 of $\mu \mathrm{l}$ antigen was mixed on a white glossy ceramic tile, with an equal volume of sheep serum. The tile was then rocked at room temperature for 4 minutes and any visible agglutination and/or the appearance of a typical rim was taken as a positive result.

\section{Immunological \& Clinical biochemical tests.}

The level of interleukin -23(IL-23) estimated by ELISA according to manual procedure of cusabio Biotech(Germany) was estimated by ELISA according to the manual procedure of 
Creative - Diagnostic Company. Copper, Zinc and acidphosphatase Concentration determined according to manufactures instructions of Biosystem(Spain).

\section{Statistical Analysis}

The results were analyzed using statistical system SPSS version -18 (T-testing).

\section{RESULTS}

\section{Genders}

According to their gender Patients with brucellosis, were studied, among them 10 were males and 8 were females. Males to females ratio was1.25 (Table 1).

Table 1. Distribution of Brucella patients according to gender and their percentage with RBT.

\begin{tabular}{lcc}
\hline Patients & No. & Positive cases \\
\hline Males & $72(56.25 \%)$ & $10(55.55 \%)$ \\
Females & $56(43.75 \%)$ & $8(44.45 \%)$ \\
Total & $128(100 \%)$ & $18(100 \%)$ \\
\hline
\end{tabular}

\section{Clinical study}

Comparing the prevalence of different clinical sign and symptoms in brucellosis as clearly in (Table 2).

Table 2. Prevalence of different clinical sign and symptoms in Brucellosis cases.

\begin{tabular}{lcc}
\hline $\begin{array}{l}\text { Sign and } \\
\text { Symptoms }\end{array}$ & No. & percentage \\
\hline Fever & & \\
Sweating & 18 & $100 \%$ \\
Malaise & 16 & $88.88 \%$ \\
Rigor & 17 & $94.44 \%$ \\
Muscle pain & 14 & $77.77 \%$ \\
Splenomegaly & 15 & $83.33 \%$ \\
Hepatomegaly & 9 & $50 \%$ \\
Lymph node enlargement & 10 & $55.55 \%$ \\
Abdominal pain & 3 & $16.66 \%$ \\
Loss of weight & 2 & $11.11 \%$ \\
Headache & 10 & $55.55 \%$ \\
Jaundice & 15 & $83.33 \%$ \\
Vomiting & 1 & $5.55 \%$ \\
& 2 & $11.11 \%$ \\
\hline
\end{tabular}

\section{Diagnosis of Brucella}

The titer of 1:160 of antibodies to Brucella present in 12 cases with a percent of $66.66 \%$, also, the titer of 1:320 of antibodies to Brucella present in 6 cases with a percent of $33.34 \%$ out of 128 cases in RBT method (Table 3 ).

Table 3. Distribution of Brucella patients according the antibodies titer with RBT.

\begin{tabular}{ccc}
\hline Titer & No. & Percentage \\
\hline $1: 160$ & 12 & $66.66 \%$ \\
$1: 320$ & 6 & $33.34 \%$ \\
Total & 18 & $100 \%$ \\
\hline
\end{tabular}

\section{Zinc and Copper}

The concentration of zinc showed non significantly $(p \geq 0.05)$ in both interval ages of patients with brucellosis in comparison with healthy control (Table 4). Also, the result of copper statistically non significant in both interval ages of patients and healthy control.

Table 4. Zinc and copper concentration $(\mathrm{mmol} / \mathrm{l})$ in patients with Brucellosis and healthy control.

\section{Parameter}

Age categories

\begin{tabular}{cccccc} 
& \multicolumn{2}{c}{ Zinc } & & \multicolumn{2}{c}{ Copper } \\
\cline { 2 - 3 } \cline { 5 - 6 } & Patients & Control & & Patients & Control \\
\hline $17-36$ & $9.4 \pm 0.3$ & $10.2 \pm 1.1$ & $12.0 \pm 2.3$ & $11.9 \pm 1.8$ \\
$37-69$ & $10.4 \pm 0.7$ & $10.9 \pm 4.2$ & $13.3 \pm 2.6$ & $11.2 \pm 2.2$ \\
\hline
\end{tabular}

\section{Acidphosphatase activity}

The activity of acid phosphatase increased significantly ( $\mathrm{pd} \leq .05$ ) in both interval ages of brucellosis patients in comparison with healthy control (Table 5).

Table 5. Acid phosphatase activity in patients with Brucellosis and healthy control.

\begin{tabular}{lcc}
\hline $\begin{array}{l}\text { Patients } \\
\text { Age Categories }\end{array}$ & Acid phosphatase $(1 \mathrm{U} / \mathrm{ml})$ \\
\hline $17-36$ & Patients & $0.8 \pm 0.2^{*}$ \\
& Control & $0.3 \pm 0.2$ \\
$37-69$ & Patients & $0.7 \pm 0.3^{*}$ \\
& Control & $0.5 \pm 0.1$ \\
\hline
\end{tabular}

$* p d \leq 0.05$ 


\section{Interleukin-23}

The level of IL-23 Increased siginifigantly( $\mathrm{pd} \leq 0.05)$ in patients with Brucellosis in comparison with healthy control in both interval ages the value $327,388 \mathrm{pg} \mathrm{ml}$ for patients and 264 , $268 \mathrm{pg} \mathrm{ml}$ for healthy control respectively (Table $6)$.

Table 6. Concentration of IL-23 pg/ml in patients with Brucellosis and healthy control.

\begin{tabular}{llc}
\hline $\begin{array}{l}\text { Parameter } \\
\text { Age Categories }\end{array}$ & \multicolumn{2}{c}{$\mathrm{IL}-23(\mathrm{pg} / \mathrm{ml})$} \\
\hline $17-36$ & Patients & $327+32^{*}$ \\
& Control & $264+18$ \\
$37-69$ & Patients & $388+16^{*}$ \\
& Control & $268+17$ \\
\hline
\end{tabular}

$* p d \leq 0.05$

\section{DISCUSSION}

Brucellosis is a common Zoonotic disease of worldwide distribution. It continues to be a serious public health issue in Iraq, especially in epidemiological region in Iraq because population who consumes unpasteurized dairy products like milk, cheese and also population who contact with infected animals . diagnosis of brucellosis is only made after the causative organism is unexpectedly detected in cultures of blood or exudates specimens or serological test like: Rose Bengal test ${ }^{18}$. Although high percentage of false negative results is reported, the most common serologic test used in our country is Rose Bengal test (RBT). There is an association of direct and indirect laboratorial tests with clinical and epidemiological data is essential to perform a definitive diagnosis of brucellosis ${ }^{19}$.

The incidences of brucellosis among males were more common than females (Table 1 ), although brucellosis affects both sexes $(1,8)$ and compatible with other reports ${ }^{20,21}$. high proportion of brucellosis cases with fever, brucellosis should be considered as a differential diagnosis for fevers of unknown origin. Arthralgia, myalgia, and back pain were common manifestations. The relative lower proportions of patients with vomiting and Jaundice compared to those reporting back pain might reflect limitations in diagnostic capacity
(Table 2) the result in line with Dean et al(22) the result indicated no statistically difference in zinc and copper concentration in patients and healthy control serum (Table 4). The result compatible with(23). Infection may also affect serum trace element concentration due to altered or impaired liver physiology or increased loss in the urine. In a general , Immunity and resistance to infection is affected by the nutritional status.

Micronutrients such as $\mathrm{Zn}$ and $\mathrm{Cu}$ may affect and modulate immune responses and thereby contribute to resistance to infectious diseases $24,25,26$. Acid phoshatase increased significantly in patients with Brucellosis (Table 5) in a general, ACP considered as a virulence factor in some pathogenic microorganism or may be important for management of disease severity ${ }^{27}$ The increasing level of IL-23 may be produced mainly by activated antigen-presenting cells (APC) including dendritic cells (DC).

The activation of DC plays a pivotal role in shaping the immune responses. Following the detection of microbial products, for example via TLRs, activated DC can provide signals to prime naïve $T$ cells to mount appropriate adaptive immune response in a general, Lps of Gramnegative bacteria prime DC for enhanced IL-23 expression Via production of prostaglandin E2 to induced both the expression of IL-23p19 and IL-12p40 without affecting IL-12p35 expression in $\mathrm{DC}^{28,29}$.

\section{CONCLUSION}

The result indicated that Rose Bengal test positive in 18 cases 12 with a titer of 1:160 and 6 cases with a titer of 1:320. The Level of IL-23, Acid phosphatase increased significantly, with no statistical difference in copper and zinc concentration in both interval ages of patients sera in comparison with healthy control.

\section{CONFLICT OF INTEREST}

Authors declare that there is no conflict of interest

\section{REFERENCES}

1. AL-Khafaji J. K. 2003. Brucellosis among human populations in AL-Musaib. District, Babylon province/Iraq. AL-Mustansiriyah Scientific 
Journal. 14(1): 25-29.

2. Bechtol D., Carpenter L. R., Mosites E., Smalley D. and Dunn J. R. 2010. Brucella melitensis Infection Following Military Duty in Iraq. Zoonoses Public Health. https://doi.org/10.1111/j.18632378.2011.01399.x

3. Jaff D. 2016. Brucellosis in Iraqi Kurdistan: An overview. Journal of Entomology and Zoology Studies. 4(4): 1113-1115.

4. Pappas G., Papadimitriou P., Akritidis N., Christou L. and Tsianos E. V. 2006. The new global ap of human brucellosis. Lancet Infect Dis. 6:91-99.

5. Al-Zayadi A. and Al-Yassaree S. Study the incidence of brucellosis in Samawa city. AlQadysia Journal, 2006; 5(2): 65-68.

6. Strangalis G., Singounas E., Boutsikakis I. and Saroglou G. Chronic intracerebral Brucella abscess, Case illustration. Journal of Neurosurgery. 2000; 92(1):189-191.

7. Young E. J. An overview of human Brucellosis. Clinical Infectious Diseases. 1995; 21: 283-290.

8. Dahouk S. A., Neubauer H., Hensel A., Schoneberg I., Nockler K., Alpers K., Merzenich H., Stark K. and Jansen A. Changing epidemiology of human brucellosis, Germany, 1962-2005. Emerging Infectious Diseases. 2007; 13: 18951900.

9. Glynn M. K. and Lynn T. V. Brucellosis. Journal of the American Veterinary Medical Association. 2008; 233: 900-908.

10. Jaff D. Brucellosis in Iraqi Kurdistan: An overview. Journal of Entomology and Zoology Studies. 2016; 4(4): 1113-1115.

11. Oliveira S. C. and Splitter G. A. CD8+ type 1 CD44hi CD45 RBlo T lymphocytes control intracellular Brucella abortus infection as demonstrated in major histocompatibility complex class I- and class II-deficient mice. European Journal of Immunology. 1995; 25(9): 2551-2557.

12. Bouhet S., Lafont V., Billard E., Gross A. and Dornand J.The IFN gamma induced STAT1-CBP/ P300 association, required for a normal response to the cytokine, is disrupted in Brucella-infected macrophages. Microbiology and Pathology. 2009; 46: 88-97.

13. Brandão A. P., Oliveira F. S., Carvalho N. B., Vieira L. Q., Azevedo V., Macedo G. C. and Oliveira S. C. Host susceptibility to Brucella abortus infection is more pronounced in IFN-knockout than IL-12/2-microglobulin double-deficient mice. Clinical and Developmental Immunology E-pub. 2012; 2012: 1-7. doi:10.155/2012/589494.

14. Spera J. M., Ugalde J. E., Mucci J., Comerci D. J. and Ugalde R. A. -AB lymphocyte mitogen is a Brucella abortus virulence factor required for persistent infection. Proceedings of the National Academy of Sciences of the United States of America (PNAS). 2006; USA103, 16514-16519

15. Iwasaki A. and Medzhitov R. Toll-like receptor control of the adaptive immune responses. Nature Immunology. 2004; 5: 987-995.

16. Jimenez-De M.P., Dudal S., Dornand J. and Gross A. Cellular bioterrorism: how Brucella corrupts macrophage physiology to promote invasion and proliferation. Clinical Immunology. 2005; 114: 227-238.

17. Alton G. G., Jones L. M., Angus R. D. and Verger J. M. Techniques for the brucellosis laboratory. INRA, Paris. Ch. 2, 1988; p.114.

18. Mohammed I. S. Environmental, efface and filed study for source Brucella disease. International Journal of Advanced Research. 2015; 3(7): 177184.

19. Salih S. M., Khorsheed H. O., Ya'qob J. S. and Ameen T. S. Incidence of brucellosis in Kirkuk Province Using Simple Dilution Micro agglutination Rose Bengal Test Method. Tikrit Medical Journal. 2007; 13(1): 70-74.

20. Al-Abbasi AM., Alwan S. J. and Al-Jubbory S. F. Brucellosis in Baghdad. A study of 64 cases. Iraqi Journal Microbiology. 1991; 3(1): 34-41.

21. AL-Wash M. and Al-Wan H. Epidemiological study of brucellosis in Babylon during year 19941997. Iraqi Journal of Community Medicine. 1999; 12(2): 112-115.

22. Dean A. S., Crump L., Greter H., Hattendorf J., Schelling E. Clinical Manifestations of Human Brucellosis: A Systematic Review and MetaAnalysis. PLOS Neglected Tropical Diseases. 2012; 6(12): e1929. doi:10.1371/journal. pntd.0001929.

23. Ahmadreza M., Hajiab D., Siroos J., Ali A., Mehdi A., Peyman E. and Henk L. S. Serum zinc and copper concentrations in brucellosis patient. Iranian Journal of Clinical Infectious Disease. 2010; 5(2): 96-100.

24. Munoz C., Rios E., Olivos J., Brunser O. and Olivares M. Iron, copper and Immunocompetence. British Journal of Nutrition. 2007; 98: S24-S28.

25. Dardenne M. Zinc and immune function. European Journal of Clinical Nutrition. 2002; 56(3): S20-S23.

26. Shankar A. H. and Prasad A. S. Zinc and immune function: the biological basis of altered resistance to infection. American Journal of Clinical Nutrition. 1998; 68: 447S-463S.

27. Benedicta D., Rajeevalochana P. and Sreekantha V. D. Acid Phosphatase as a Marker in Malaria. 
Indian Journal of Clinical Biochemistry. 2011; 26(4): 396-399. DOI 10.1007/s12291-0110137-z.

28. Hermelijn H. Smits H., Beelen A., Hessle C., Westland R., Soeteman E., Eddy A. Wierenga E. and Kapsenberg m. Commensal Gram-negative bacteria prime human dendritic cells for enhanced IL-23 and IL-27 expression and enhanced Th1 development. European Journal of Immunology. 2004; 34: 1371-1380. https:// doi.org/10.1002/eji.200324815

29. Sheibanie A. F., Tadmori I., Jing H., Vassiliou E. and Ganea D. Prostaglandin E2 induces IL-23 production in bone marrow-derived dendritic cells. FASEB Journal. 2004; 18: 1318-1320. 